\title{
HUBUNGAN POWER OTOT TUNGKAI, KOORDINASI MATA KAKI DAN KEKUATAN OTOT PERUT DENGAN KETEPATAN MENEMBAK BOLA
}

\author{
Firman Adityatama \\ STKIP Muhammadiyah Kuningan \\ email: firmanadityatama@yahoo.com
}

\begin{abstract}
Abstrak
Tujuan penelitian ini adalah untuk mengetahui: (1) Hubungan antara power otot tungkai dengan ketepatan menembak bola ke gawang sepakbola pada pemain sepakbola kelompok umur 12 tahun klub SSB Tunas Harapan Klampok Brebes, (2) Hubungan antara koordinasi mata kaki dengan ketepatan menembak bola ke gawang sepakbola pada pemain sepakbola kelompok umur 12 tahun, (3) Hubungan antara kekuatan otot perut dengan ketepatan menembak bola ke gawang sepakbola pada pemain sepakbola kelompok umur 12 tahun, (4) Hubungan antara power otot tungkai, koordinasi mata kaki, dan kekuatan otot perut dengan ketepatan menembak bola ke gawang sepakbola pada pemain sepakbola kelompok umur 12 tahun. Metode yang digunakan deskriptif studi korelasional. Populasi dalam penelitian ini adalah pemain sepakbola kelompok umur 12 tahun klub SSB Tunas Harapan Klampok Brebes berjumlah 30 pemain, dengan teknik pengambilan sampling yang digunakanadalah purposive sampling. Teknik pengumpulan data dilakukan dengan tes dan pengukuran dalam olahraga yaitu; (1) power otot tungkai dengan standing broad jump test, (2) koordinasi mata kaki dengan soccer wall voley test, (3) kekuatan otot perut dengan sit-up test, (4) ketepatan menembak bola ke gawang sepakbola menggunakan petunjuk tes menembak bola ke dalam gawang.Teknik analisis data dilakukan dengan analisis statistik menggunakan korelasi product moment dan analisis regresi tiga prediktor pada taraf signifikansi 5\%. Penelitian ini menghasilkan simpulan sebagai berikut: (1) ada hubungan yang signifikan antara power otot tungkai dengan ketepatan menembak bola ke gawang sepakbola pada pemain sepakbola kelompok umur 12 tahun klub SSB Tunas Harapan Klampok Brebes. (2) ada hubungan yang signifikan antara koordinasi mata kaki dengan ketepatan menembak bola ke gawang sepakbola pada pemain sepakbola kelompok umur 12 tahun. (3) ada hubungan yang signifikan antara kekuatan otot perut dengan ketepatan menembak bola ke gawang sepakbola pada pemain sepakbola kelompok umur 12 tahun. (4) ada hubungan yang signifikan antara power otot tungkai, koordinasi mata kaki dan kekuatan otot perut dengan ketepatan menembak bola ke gawang sepakbola pada pemain sepakbola kelompok umur 12 tahun.
\end{abstract}

Kata Kunci: Power Otot Tungkai, Koordinasi Mata Kaki, Kekuatan Otot Perut Ketepatan Menembak Bola.

\footnotetext{
Abstract

The purpose of this research is to know: (1) The relationship between leg muscle strength with the precision of shooting the ball into the soccer on the club football player of 12 years old club SSB Tunas Harapan Klampok Brebes, (2) The relationship between the coordination of the ankle with the precision of shooting the ball into the soccer on the football player of the club's age group 12 years SSB Tunas Harapan Klampok Brebes, (3) The relationship between
} 
abdominal muscle strength with the precision of shooting the ball into the soccer on the club of 12-year-old football club club SSB Tunas Harapan Klampok Brebes, (4) The relationship between leg muscle power, foot coordination, and abdominal muscle strength with precision shooting ball To the soccer goalkeeper on the 12-year-old football club of SSB club Tunas Harapan Klampok Brebes. In accordance with the purpose of research, this research using descriptive method correlational study. The population in this study is the football player of 12year-old club club SSB Tunas Harapan Klampok Brebes, amounting to 30 players, with sampling technique used is purposive sampling. Technique of data collecting done by test and measurement in sport that is; (1) leg muscle power with standing broad jump test, (2) foot coordination with soccer wall voley test, (3) abdominal muscle strength with sit-up test, (4) precise shooting ball to soccer goal using shooting test Into the goal. Data analysis technique is done by statistical analysis using product moment correlation and regression analysis of three predictors at 5\% significance level. This research yields the following conclusion: (1) there is a significant relationship between leg muscle power with the accuracy of shooting the ball into the football goal on the soccer player of the age group of 12 years club SSB Tunas Harapan Klampok Brebes, $r_{\text {count }}=0.488>r_{\text {table }} 5 \%=0.361$, (2) there is a significant relationship between Eye coordination with the precision of shooting the ball into the soccer on the club of 12 years old club club SSB Tunas Harapan Klampok Brebes, $\left.r_{\text {count }}=0.414>r_{\text {table }} 5 \%=0.361,3\right)$ there is a significant correlation between abdominal muscle strength with the accuracy of shooting ball to the soccer on the club of 12 years old club club SSB Tunas Harapan Klampok Brebes, $r_{\text {count }}=$ $0,424>r_{\text {table }} 5 \%=0,361$, (4) there is significant relation between Leg muscle power, foot coordination and abdominal muscle strength with precision shooting ball into soccer on club of 12 years old club of club SSB Tunas Harapan Klampok Brebes, $F_{\text {count }}=3,6291>F_{\text {table }}=2,89$.

Keywords: The relationship between leg muscle power, foot coordination and abdominal muscle strength to the accuracy shooting of soccer.

(C) 2017 STKIP Muhammadiyah Kuningan 


\section{PENDAHULUAN}

Proses pembinaan olahraga di Indonesia saat ini belum maksimal. Hal ini terbuktidaripertandingan dan perlombaan yang telah diikuti belum menunjukkan hasil yang memuaskan. Proses pembinan olahragainiharusnya di pahami sebagai suatu sistem yang kompleks, sehingga masalah yang terdapat didalamnya perlu ditelaah dari sudut pandang yang luas.Pembinaan sebagaimana yang dimaksud antara lain dapat dilakukan pada aspek gerakan. Gerakan-gerakan dalam bidang olahraga diharapkan dilakukandengan cara efisiendan teknikyang benar. Gerakan dikatakan efisien apabila gerakan-gerakan yang terkoordinasi dengan baik dikombinasikan untukmenghasilkan gerakan yang diperlukan untuk menyelesaikan tugas tertentu, dan memanfaatkannya dengan perolehan nilai yang tinggi, dengan arah yang baik, dan menggunakan tenaga sekecil mungkin.Seseorang yang mampu melakukan gerakan-gerakan secara efisien, orang tersebut dapat dikatakan terampil.

Pemecahan masalah prestasi olahraga harus ditinjau dari ilmu pengetahuan agar mencapai sasaran tertentu yaitu pencapaian prestasi maksimal. Menurut Mochamad Sajoto (1995:3-5), prestasi olahraga ditentukan oleh beberapa faktor, diantaranya adalah: (1) faktor biologis, (2) faktor psikologis, (3) faktor lingkungan dan (4) faktor penunjang.Faktor biologis atau fisik yaitu yang berkaitan dengan struktur, postur dan kemampuan biomotorik yang ditentukan secara genetik merupakan salah satu faktor penentu prestasi yang terdiri dari beberapa komponen dasar yaitu: kekuatan (strength), kecepatan (speed), kelentukan (flexibility), kelincahan (agility), daya tahan (endurance), daya ledak (explosive power), keseimbangan (balance), koordinasi (coordination).

Sepakbola merupakan salah satu cabang olahraga pada masyarakat Indonesia. Dalam melakukan permainan sepakbola ada yang bertujuan untuk rekreasi dan ada juga yang untuk prestasi. Sepakbola adalah suatu permainan yang dimainkan secara tim yang setiap tim terdiri dari sebelas orang sehingga diperlukan suatu kerjasama tim dan keterampilan dari masing-masing individu yang mana di dalamnya terkandung beberapa unsur kondisi fisik yang harus diperlukan dalam permainan sepakbola. Selain unsur kondisi fisik, seorang pemain 
sepakbola juga harus menguasai berbagai teknik dasar dalam bermain sepakbola seperti passing, dribbling dan shooting. Latihan-latihan teknik membantu pemain mengembangkan keterampilan yang harus dikuasai untuk bermain sepakbola (Koger, 2005: 2).

Sepakbola termasuk permainan yang komplek gerakannya yaitu terdiri darigabunganunsur-unsur gerak yang terkoordinasi dengan rapi sehinggamemerlukanwaktu cukup lama untuk menguasai teknik dasar permainan sepakbola denganbenar. Dengan penguasaan teknik dasar yang benar maka akan menunjangketerampilan selanjutnya. Untuk mendapatkan gerakan efektif dan efisien, perlupenekanan pada penguasaan teknik dasar yang baik.

Pemain kelompok umur 12 tahun klub SSB Tunas Harapan Klampok Brebes dalam melakukan ketepatan menembak bola ke gawang sepakbola sering kurang maksimal sehingga banyak peluang untuk mencetakgol terbuang dengan percuma dan juga sering terjadi kesulitan dalam melakukan ketepatan menembak bola ke gawang sepakbola sepakbola. Agar ketepatan menembak bola ke gawang sepakbola dapat dilakukan dengan baik, terlebih dahulu perlu dikaji faktor-faktor yang mempengaruhi ketepatan menembak bola ke gawang sepakbola perlu ditelusuri faktor penyebabnya. Dimana faktor-faktor yang mempengaruhi ketepatan menembak bola ke gawang sepakbola diperlukan unsur-unsur kondisi fisik seperti: kekuatan, kecepatan, kelenturan, keseimbangan, ketepatan, daya tahan, kelincahan, dan koordinasi.

Ada beberapa faktor penyebab kurang berhasilnya proses latihan permainan sepakbola yaitu terbatasnya sumber-sumber yang digunakan pelatih untuk mendukung proses latihan dan terbatasnya kemampuan pelatih.Kenyataan yang terjadisaat ini, pelatih dihadapkan dengan keterbatasan waktu serta tidak memadainya alat-alat yang tidak sesuai dengan jumlah pemain yang akan dilatih sementara banyak materi yang akan dilatih kepada pemain. Permasalahan ini tentunya salah satu disebabkan keterbatasan kemampuan dan kualitas pelatih sepakbola dalam mengelola dan memodifikasi metode latihan.

Ketepatan menembak bola ke gawang sepakbola memiliki tingkat kerumitan dan kompleksitas yang berbeda-beda, baik dari keterampilan 
yang mudah sampai keterampilan yang semakin sulit, dan dari keterampilan yang sederhana sampai pada keterampilan yang kompleks. Dipandang dari tingkat kesulitan dan kompleksitas, ketepatan menembak bola ke gawang sepakbola memiliki tingkat kesulitan dan kompleksitas yang tinggi karena mencakup unsur-unsur: koordinasi mata kaki, timing, tempo, keseimbangan dan akurasi. Ketepatan menembak bola ke gawang sepakbola merupakan suatu teknik dasar yang harus dikuasai setiap pemain sepakbola tanpa terkecuali. Ketepatan menembak bola ke gawang sepakbola adalah suatu teknik dasar menembak yang sering digunakan oleh setiap pemain untuk mencetakgol dalam setiap pertandingan.Ketepatan menembak bola ke gawang sepakbola dapat dilakukan oleh setiap pemain, biasanya dalam suatu tim sepakbola.Ketepatan menembak bola ke gawang sepakbola hanya dimiliki oleh seorang pemain yang berkarakter sebagai seorang pemain penyerang tetapi pada kenyataannya sekarang ketepatan menembak bola ke gawang sepakbola dapat dilakukan oleh setiap pemain dalam suatu tim, karena kemenangan suatu pertandingan ditentukan oleh jumlah poin yang dihasilkan melalui tembakan yang dibuat suatu tim.

Ketepatan menembak bola ke gawang sepakbola merupakan salah teknik dasar dalam sepakbola namun cukup sulit dipelajari, lebih-lebih untuk pemain yang belum terampil.Tujuan dalam permainan sepakbola adalah untuk menciptakan tembakan yang tepat dan mendapat angka pada setiap kesempatan, yang merupakan syarat tim tersebut dinyatakan pemenang. Dengan demikian keterampilan gerak dasar menembak (shooting) dalam permainan sepakbola sangat penting untuk dikuasai secara baik, tetapi tidak boleh mengesampingkan keterampilan gerak dasar yang lain. Tingkat keberhasilan pemain memasukkan bola ke gawang dapat dipengaruhi oleh kebiasaan dan penguasaan teknik menembak yang baik.

Perbedaan kemampuan terutama terjadi karena kualitas fisik yang berbeda

(Sugiyanto,1997:353).Kemampuan fisik berhubungan dengan power otot tungkai, koordinasi mata kaki, dan kekuatan otot perut yang mempengaruhi penampilan seseorang baik dalam latihan gerakan-gerakan keterampilan maupun dalam penampilan.Dengan 
demikian dapat dikatakan power otot tungkai, koordinasi mata kaki, dan kekuatan otot perut yang baik adalah suatu persyaratan dalam usaha mencapai prestasi maksimal bagi seseorang dalam latihan ketepatan menembak bola ke gawang sepakbola. Power otot tungkai, koordinasi mata kaki, dan kekuatan otot perut yang ada pada pemain harus menjadi pertimbangan sebagai suatu faktor yang menentukan dalam ketepatan menembak bola ke gawang sepakbola yang sesuai dengan karakter dari masing-masing pemain sehingga bisa mencapai hasil latihan yang optimal sesuai dengan potensi yang dimiliki.

Untuk mengetahui power otot tungkai, koordinasi mata kaki, dan kekuatan otot perut memiliki hubungan dengan ketepatan menembak bola ke gawang sepakbola, maka perlu dilakukan penelitian berjudul "Hubungan Antara Power Otot Tungkai, Koordinasi Mata Kaki dan Kekuatan Otot Perut dengan Ketepatan Menembak Bola Ke Gawang Sepakbola Pada Pemain Sepakbola Kelompok Umur 12 Tahun Klub SSB Tunas Harapan Klampok Brebes".

METODE
Metode penelitian yang digunakan adalah metode deskriptif studi korelasional. Dalam hal ini Sugiyanto (1995: 57) berpendapat bahwa "melalui studi korelasional dapat diketahui apakah satu variabel berasosiasi dengan variabel yang lain. Hubungan antara variabel ditentukan dengan menggunakan koefisien yang dihitung dengan teknik analisis statistik". Penelitian ini untuk mengetahui hubungan antara power otot tungkai, koordinasi mata kaki, dan kekuatan otot perut dengan ketepatan menembak bola ke gawang sepakbola.

Sesuai dengan judul penelitian ini, maka penelitian ini terdiri beberapa variabel. Menurut Sugiyanto (1995: 17) variabel adalah "suatu konsep yang dapat ditempatkan dalam berbagai nilai yang berbeda". Variabel dalam penelitian ini terdiri dari:

1) Variabel bebas yaitu variabel yang mempengaruhi variabel lain. Variabel bebas dalam penelitian ini yaitu power otot tungkai, koordinasi mata kaki dan kekuatan otot perut.

2) Variabel terikat adalah variabel yang dipengaruhi oleh variabel lain. Variabel terikat dalam penelitian ini yaitu ketepatan menembak bola ke gawang sepakbola. 
Populasi dan sampel penelitian ini adalah pemainsepakbola kelompok umur 12 tahun klub SSB Tunas Harapan Klampok Brebes. Teknik sampel yang digunakan adalah purposive sampling dengan teknik undianyang berjumlah 30 pemain.

Teknik pengumpulan data menggunakanpetunjuk tes:

1) Tes dan pengukuran power otot tungkai dengan standing broad jump test (Johnson and Nelson, 1986: 212).

2) Tes dan pengukuran koordinasi mata kaki dengan soccer wall voley test (Kirkendall, Gruber \& Johnson, 1980: 247-248).

3) Tes dan pengukuran kekuatan otot perut dengan sit-up test dari Ismaryati (2008: 119).

4) Tes dan pengukuran ketepatan menembak bola ke gawang sepakbola menggunakan petunjuk tes menembak bola ke dalam gawang (Plooyer, 1970: 152-157). Petunjuk pelaksanaan masingmasing tes dan pengukuran variabel penelitian terlampir.

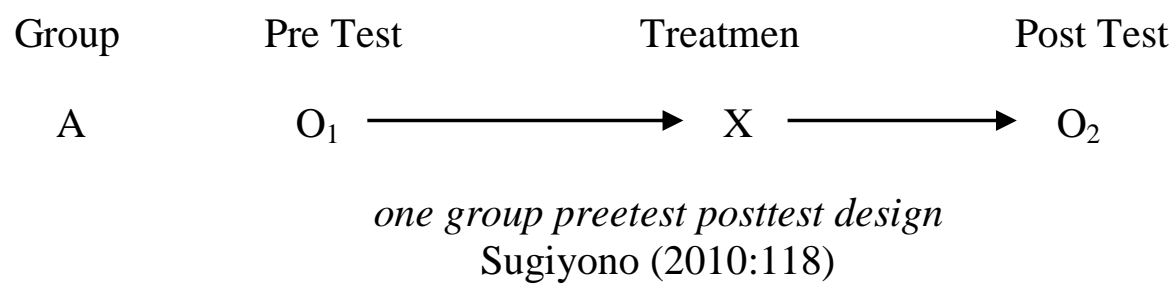

\section{HASIL PENELITIAN}

Hasil penelitian yang disajikan adalah hasil dari analisis yang telah dilakukan terhadap data dari tiap variabel. Data dari masing-masing variabel yangdiambil dalam penelitian, terdiri dari tiga variabel bebas yaitu power otot tungkai, koordinasi mata kaki dan kekuatan otot perut, dan satu variabel terikat yaitu ketepatan menembak bola ke gawang sepakbola.
Berturut-turut dalam bab ini disajikan mengenai deskripsi data, pengujian persyaratan analisis, hasil analisis data dan pengujian hipotesis.

Power otot tungkai merupakan komponen penting yang diperlukan padasepakbola.Ketepatan menembak bola ke gawang sepakbola dilakukandengantepat dan jelas melakukan tembakan pada salah satu 
kaki yang akan membantu efisiensi dan efektifitas gerakan yang dilakukan. Gerakanmenembak bola ke gawang sepakbolamemerlukan power otot tungkai.Keberhasilan dan pencapaian hasil ketepatan menembak bola ke gawang sepakbola dipengaruhi oleh power otot tungkai yang dimiliki.Dengan demikian dapat disimpulkan bahwa power otot tungkai memiliki hubungan dengan ketepatan menembak bola ke gawang sepakbola.Sehingga hipotesis yang menyatakan bahwa power otot tungkai memiliki hubungan dengan ketepatan menembak bola ke gawang sepakbola dapat diterima kebenarannya.

\section{Hubungan Antara Koordinasi} Mata Kaki dengan Ketepatan Menembak Bola Ke Gawang Sepakbola

Koordinasi mata kaki diperlukanpada saat pemainmelakukan ketepatan menembak bola ke gawang sepakbola. Makin baik koordinasi mata kaki yang dimiliki oleh pemain, maka akan semakin baikketepatan menembak bola ke gawang sepakbola yang akan dicapai. Dengan demikian dapat disimpulkan bahwa koordinasi mata kaki memiliki hubungan dengan ketepatan menembak bola ke gawang
sepakbola.Sehingga hipotesis yang menyatakan bahwa koordinasi mata kaki memiliki hubungan dengan ketepatan menembak bola ke gawang sepakbola dapat diterima kebenarannya.

\section{Hubungan Antara Kekuatan Otot Perut dengan Ketepatan Menembak Bola Ke Gawang Sepakbola}

Berdasarkan hasil analisis data dapat diketahui bahwa kekuatan otot perut memiliki hubungan dengan ketepatan menembak bola ke gawang sepakbola.Nilai hubungan kekuatan otot perut terhadap kemampuan ketepatan menembak bola ke gawang sepakbola cukup signifikan.Kekuatan otot perut diperlukan untuk menunjang ketepatan menembak bola ke gawang sepakbola.Gerakan menembak bola ke gawang sepakbola merupakan gerakan yang menggunakan kekuatan otot perut.Dalam melakukan gerakan ketepatan menembak bola ke gawang sepakbola seorang pemain dituntut agar sikap badan saat menembak bola ke gawang sepakbola harus dijaga dengan kekuatan otot perut.Sehingga hipotesis yang menyatakan bahwa kekuatan otot perut memiliki hubungan dengan ketepatan menembak bola ke gawang sepakbola dapat diterima kebenarannya. 
3. Hubungan Power Otot Tungkai, Koordinasi Mata Kakidan Kekuatan Otot Perut dengan Ketepatan Menembak Bola Ke Gawang Sepakbola

Untuk menguji hubungan antara power otot tungkai, koordinasi mata kakidan kekuatan otot perut dengan ketepatan menembak bola ke gawang sepakbola, dilakukan analisis regresi ganda tiga prediktor. Dari analisis regresi yang dilakukan dapat diketahui bahwa nilai $F_{\text {regresi }}$ yang diperoleh adalah 3,6291, sedangkan dengan $\mathrm{db}=$ 3 lawan 26 pada taraf signifikansi 5\%, nilai $\mathrm{F}_{\text {regresi }}$ dalam tabel adalah 2,89. Karena $F_{\text {hitung }}=3,6291>F_{\text {tabel }}=2,89$. Besarnya nilai hubungan power otot tungkai, koordinasi mata kakidan kekuatan otot perut terhadap ketepatan menembak bola ke gawang sepakbola adalah 0,295.

Dari hasil tersebut dapat disimpulkan bahwa terdapat korelasi yang signifikan antara power otot tungkai, koordinasi mata kaki dan kekuatan otot perut dengan ketepatan menembak bola ke gawang sepakbola. Dengan demikian hipotesis yang menyatakan bahwa power otot tungkai, koordinasi mata kaki dan kekuatan otot perut memiliki hubungan dengan ketepatan menembak bola ke gawang sepakbola dapat diterima kebenarannya.Besarnya nilai hubungan antara power otot tungkai $\left(\mathrm{X}_{1}\right)$, koordinasi mata kaki $\left(\mathrm{X}_{2}\right)$, kekuatan otot perut $\left(\mathrm{X}_{3}\right)$ terhadap ketepatan menembak bola ke gawang sepakbola (Y) adalah0,295. Hal ini berarti bahwa variansi ketepatan menembak bola ke gawang sepakbola dipengaruhi oleh power otot tungkai, koordinasi mata kaki dan kekuatan otot perut sebesar $29,515 \%$.

\section{SIMPULAN}

Berdasarkan hasil penelitian dan hasil analisis regresi dan korelasi product moment yang telah dilakukan dapat diperoleh simpulan sebagai berikut:

1. Ada hubungan yang signifikanantara power otot tungkai dengan ketepatan menembak bola ke gawang sepakbolapadapemain sepakbola kelompok umur 12 tahun klub SSB Tunas Harapan Klampok Brebes, $r_{\text {hitung }}=0,488>r_{\text {tabel }} 5 \%=$ 0,361 .

2. Ada hubungan yang signifikan antara koordinasi mata kakidengan ketepatan menembak bola ke gawang sepakbolapada pemain sepakbola kelompok umur 12 tahun 
klub SSB Tunas Harapan Klampok

Brebes, $r_{\text {hitung }}=0,414>r_{\text {tabel }} 5 \%=$ 0,361 .

3. Ada hubungan yang signifikan antara kekuatan otot perut dengan ketepatan menembak bola ke gawang sepakbolapada pemain sepakbola kelompok umur 12 tahun klub SSB Tunas Harapan Klampok Brebes, $r_{\text {hitung }}=0,424>r_{\text {tabel }} 5 \%=$ 0,361 .

4. Ada hubungan yang signifikan antara power otot tungkai, koordinasi mata kakidan kekuatan otot perut dengan ketepatan menembak bola ke gawang sepakbolapada pemain sepakbola kelompok umur 12 tahun klub SSB Tunas Harapan Klampok Brebes, $\mathrm{F}_{\text {hitung }}=3,6291>\mathrm{F}_{\text {tabel }}=2,89$.

\section{DAFTAR PUSTAKA}

A. Sarumpaet, Zulfar Djazet, Parno \& Imam Sadikun. 1992. Permainan Besar. Jakarta: Departemen Pendidikan dan Kebudayaan, Direktorat Jendral Pendidikan Tinggi Proyek Pembinaan Tenaga Kependidikan.

Bompa, Tudor, O. 1999. Periodization: Theory and Methodology of Training.Kendall/Hunt Publishing Company.

Engkos Kokasih. 1993. Olahraga Teknik dan Program Latihan. Jakarta: Akademi Presinddo.

Eric, Batty C. 2003. Latihan Sepak Bola Metode Baru Serangan. Bandung: Pioner Jaya.
Fuchs, Erich, Dieter Kruher and Gunter Jansen. 1981. Sepak Bola: Pembinaan Teknik dan Kondisi. (Terjemahan: Agus Setiadi). Jakarta: Penerbit PT. Gramedia.

Hamidsyah Noer. 1996. Ilmu Kepelatihan Lanjut. Surakarta: Universitas Sebelas Maret Surakarta.

Harsono. 1988. Coaching Dan AspekAspek Psikologis Dalam Coaching. Jakarta: Ditjen Dikti.

Ismaryati. 2008. Tes dan Pengukuran Olahraga. Cetakan 2. Surakarta: LPP UNS dan UNS Press.

Johnson, B. L. \& Nelson, J. K. 1986.Practical Measurement for Evaluation in Physycal Education. New York: Macmillan Publishing Company.

Kirkendall DR. Gruber JJ. \&Johnson RR. 1980. Measurement and Evolution For Phisical Educators. Lowa : Wm. C.Company Publiser.

Koger, Robert L. 2005. Latihan Dasar Andal Sepak Bola Remaja. New York: United States of America.

Mochamad Sajoto. 1995. Peningkatan dan Pembinaan Kondisi Fisik Dalam Olahraga. Semarang: Dahara Prize.

Mulyono BiyaktoAtmojo. 2008. Tes dan Pengukuran Dalam Pendidikan Jasmani Olahraga. Surakarta: Universitas Sebelas Maret Press.

Pearce, Evelin C. 1989. Anatomi dan Fisiologi untuk Paramedis. Jakarta: PT. Gramedia Pustaka Utama.

Plooyer, Siem. 1970. Jeugd Voetball, KNVB. Jeugdvoetball. Seriedeel G. The Football Association.Skilfull Soccer for Young Players. London: Educational Production Ltd.

Pyke, F.S. 1991. Toward Better Coaching The Art and Science of 
Coaching. Canbera, Australia: Government Publishing Service.

Ramadan, G. (2017). Pengaruh Metode Pembelajaran Dan Motivasi Belajar Terhadap Hasil Belajar Passing Sepakbola. JUARA : Jurnal Olahraga, 2(1), 1-10. Retrieved from http://jurnal.upmk.ac.id/index.php/ju ara/article/view/27

Sloane, Ethel. 2004. Anatomy and Phsylogy an Easy Learner (Edisi Terjemahan oleh Palupi Widyastuti). Jakarta: Penerbit Buku Kedokteran EGC.

Sneyers, Jeff. 1998. Sepak Bola Latihan dan Strategi Bermain. (Alih Bahasa: L. Lanjang) Jakarta: PT. Rosdo Jaya Putra Offset.

Soedarminto.

1991.Kinesiologi. Surakarta: FKIP-UNS.
Strand, B.N.\& Wilson,R. 1993. Assesing Sport Skill. Champaign: Human Kinetics Publishers.

Sudjana. 2002. Desain dan Analisis Eksperimen. Bandung: Tarsito.

Sugiyanto. 1995. Metodologi Penelitian. Surakarta: UNS Press. 1997. Perkembangan Gerak. Surakarta: UNS Press.

Suharno HP. 1993. Ilmu Coaching Umum. Yogyakarta: IKIP Yogyakarta Press.

Sutrisno Hadi. 1982. Analisis Regresi. Yogyakarta: Andi Offset. 2004. Statistik Jilid 2. Yogyakarta: Andi Offset.

Syaifudin. 1997. Fisiologi Untuk Perawat. Jakarta: EGC 